\title{
Modeling the effects of pharmaceutical marketing
}

\author{
Peter S. H. Leeflang • Jaap E. Wieringa
}

Published online: 13 October 2009

(C) The Author(s) 2009. This article is published with open access at Springerlink.com

\begin{abstract}
Successful innovation of prescription drugs requires a substantial amount of marketing support. There is, however, much concern about the effects of marketing expenditures on the demand of pharmaceutical products (Manchanda et al., Market Lett 16(3/4):293-308, 2005). For example, excessive marketing could stimulate demand for products in the absence of a fundamental need. It also has been suggested that increased marketing expenditures may reduce the price elasticity of demand and allow firms to charge higher prices (Windmeijer et al., Health Econ 15(1):5-18, 2005). In this paper, we present the outcomes of an empirical study in which we determine the effects of pharmaceutical marketing expenditures using a number of frequently used "standardized" models. We determine which models perform best in terms of predictive validity and adequate descriptions of reality. We demonstrate, among others, that the effects of promotional efforts are brand specific and that most standardized models do not provide adequate descriptions of reality. We find that marketing expenditures have no or moderate effects on demand for pharmaceutical products in The Netherlands.
\end{abstract}

Keywords Effects of pharmaceutical marketing - Drug price elasticity · Marketing model building

\footnotetext{
P. S. H. Leeflang $\cdot$ J. E. Wieringa $(\bowtie)$

Department of Marketing, Faculty of Economics and Business, University of Groningen, P.O. Box 800, 9700 AV Groningen, The Netherlands

e-mail: j.e.wieringa@rug.nl

P. S. H. Leeflang

e-mail: p.s.h.leeflang@rug.nl
} 


\section{Introduction}

The pharmaceutical industry plays a vital role in health care. In the United States, the health care industry accounts for $16 \%$ of the gross national product, a percentage expected to increase in the near future, though the growth rate is slowing (Catlin et al. 2007). Revenues generated by US pharmaceutical firms have increased at a faster rate than those of most other health care components (Peters 2004). For example, in 1990 , expenditures on pharmaceuticals as a fraction of total health care expenditures in the United States amounted to $5.6 \%$; by 2007 , that percentage had grown to $10.2 \%$ (CMS 2009).

Although prescription drugs and medical devices can improve the health of patients suffering from chronic diseases and reduce total health care expenditures, the pharmaceutical industry faces significant criticism for several reasons, including the profitability of the sector and its widely debated marketing efforts. In particular, marketing is said to reduce price sensitivity of demand for prescription drugs, leading to negative welfare effects. So, for example, Hurwitz and Caves (1988), Rizzo (1999), and Windmeijer et al. (2005) find that marketing expenditures lower price sensitivity and conclude that marketing expenditures mainly have a persuasive effect.

These findings are in contrast to Leffler (1981) who identifies an informative effect of marketing efforts because they increase price sensitivity. Some studies report strongly positive effects of direct-to-customer advertising (Rosenthal et al. 2003), whereas others reveal negative elasticities (Ling et al. 2002). Mixed findings motivate us to evaluate model structures and to assess the assumptions on which these models are based. We also want to investigate what effects these assumptions have on model outcomes.

Many models that have been developed to investigate pharmaceutical promotional marketing effects are based on pooled data and hence use a specific but very restricted model. Data are pooled over (1) different brands, which are (2) in different stages of their product life cycle and pertain to (3) different product categories. For example, Rizzo's (1999) model estimates the effects of promotional efforts on demand and the price elasticity of demand for antihypertensive drugs. In turn, Rizzo's model has been slightly modified in a study by Windmeijer et al. (2005), which is based on De Laat et al. (2002). Their study considers the following research questions:

a. What is the price elasticity of demand for prescription drugs?

b. What is the effect of promotion on sales, and how much of the effect is due to "market stealing" versus "market making"?

c. Does marketing change the price elasticity of demand?

The answers to these questions constitute important input for political debate about policy interventions on pharmaceutical markets in The Netherlands. However, the answers are based on demand equations that are pooled across (140) brands and (11) product categories. Furthermore, in these models, the marketing expenditures are aggregated over all marketing instruments and dynamics are not modeled appropriately. Finally, the demand equations contain prices, but neither prescribers nor consumers are likely to respond to pharmaceutical prices. Hence, we have doubts about the model's outcomes. 
In this study, we develop models to determine the effects of promotional marketing effects on sales which:

a. are, at least in principle, unique for each brand in each category, and hence,

b. are not based on pooled data.

We demonstrate that the parameters show large variations in parameter values and that less restricted models have better statistical and predictive validity. We also demonstrate that conclusions of previous studies are based on incorrect model assumptions. Specifically, in contrast to earlier findings, we do not find evidence for persuasive effects of marketing expenditures. Based on the outcomes of a more appropriate model, we conclude that the pooled analysis suggest stronger effects of marketing expenditures than can be substantiated by brand-level analyses.

This may affect welfare negatively. Overestimating the effectiveness of promotional instruments may lead to a higher, but less effective than expected, level of spending. In turn, this may lead to the unwanted effect that manufacturers raise their prices to compensate for the increased cost/sales ratio.

The order of discussion is as follows. First, we discuss a well-known model developed by Rizzo (1999) and modified by Windmeijer et al. (2005). We critically evaluate the outcomes of this model. Then, we discuss and evaluate some alternative specifications that describe demand equations for a substantial number of pharmaceutical brands in a more appropriate manner than the previous models. We estimate a number of different models using individual brand-level data for 49 brands from five product categories of the Dutch prescription drug market.

\section{The Rizzo model}

Many models attempt to determine the effects of pharmaceutical promotional efforts on the demand for pharmaceuticals. Manchanda et al. (2005) and Kremer et al. (2008) provide brief surveys; Stremersch (2008) positions the somewhat broader field of health and marketing. In this section, we discuss a well-known model developed by Rizzo (1999) and slightly modified by Windmeijer et al. (2005). Both models have been published in nonmarketing journals but are relevant for the following reasons. Firstly, Rizzo (1999) is one of the first to empirically investigate the effects of marketing expenditures on price elasticity of pharmaceutical demand. Secondly, the outcomes indicate a persuasive effect of marketing efforts and are extensively cited in the (marketing) literature (e.g., Narayanan et al. 2005; Venkataraman and Stremersch 2007). Finally, the conclusions have also had substantial impact on public policy makers' opinions concerning the welfare effects of pharmaceutical promotions (De Laat et al. 2002; Windmeijer et al. 2005). The model of Windmeijer et al. (2005) is relevant because it adapts Rizzo's model for the Dutch pharmaceutical market. Their modified Rizzo model takes the following structure:

$$
\begin{aligned}
\ln q_{i t}= & \gamma_{i}+\rho_{1} \ln q_{i, t-1}+\rho_{2} \ln q_{i, t-2}+\left(\alpha_{1}+\alpha_{2} \ln m e s_{i t}\right) \ln p_{i t}+\left(\alpha_{3}+\alpha_{4} \ln m e s_{i t}\right) \ln p c_{i t} \\
& +\alpha_{5} \ln m e f_{i t}+\alpha_{6} \ln m e s_{i t}+\alpha_{7} \ln m e f c_{i t}+\alpha_{8} \ln m e s c_{i t}+\beta X_{i t}+\varepsilon_{i t}
\end{aligned}
$$


where, for pharmaceutical product $i$ in month $t, q_{i t}$ is the number of prescriptions, defined in daily doses, a standard measure to compare drug use across different drugs; $\gamma_{i}$ is the brand-specific constant; mes $_{i t}$ is the marketing expenditures stock, namely, the stock of expenditures on detailing, advertising, and direct mail (in Euros); $p_{i t}$ is the price of the drug, calculated as the ratio of the costs and volume of sales (in Euros); $p c_{i t}$ is the average price of competing drugs for $i$; $m e f_{i t}$ is the marketing expenditure flow (i.e., current marketing expenditures); $m e f c_{i t}$ and $m e s c_{i t}$ are the marketing expenditure flow and stock of competing products for $i$, respectively; $X_{i t}$ is the vector of several additional variables, including product age (months and months squared), year and month dummies, and dummies for policy changes; and $\varepsilon_{i t}$ is the random disturbance term.

The stock variable mes $_{i t}$ in turn is defined as:

$$
\text { mes }_{i t}=\rho_{d} \text { mes }_{i, t-1}+\operatorname{mef}_{i t}
$$

where $\rho_{d}$ is the discount rate. The mesc $i t$ variable is defined analogously. If $\alpha_{2}>0$ $\left(\alpha_{4}<0\right)$, then marketing expenditures lower the absolute value of own (cross-)price elasticity of demand. The model also allows marketing expenditures to have a direct effect on the quantity demanded in the form of the parameters $\alpha_{5}-\alpha_{8}$.

This model has been estimated by Windmeijer et al. (2005) using pooled data. The authors use monthly data of 140 products from 11 therapeutic markets: allergy, anxiety, asthma, cholesterol, depression, hypertension, migraine, pregnancy, rheumatism, sleeping disorders, and ulcers. The 11 markets together cover 58\% of the total Dutch market for reimbursed prescription pharmaceuticals, as measured in pharmaceutical costs. The dataset is restricted to quantities sold on the basis of prescriptions written by general practitioners (GPs) and psychiatrists because the detailing data is based on a panel consisting of these physicians. The (pooled) estimates are summarized in Table 1.

The results in Table 1 suggest the following conclusions:

a. average premarketing own-brand price elasticity is negative $(p<0.10)$;

Table 1 Parameter estimates for the model of Windmeijer et al. (2005)

\begin{tabular}{llr}
\hline Coefficient of & & Estimate \\
\hline $\ln q_{i, t-1}$ & $($ lag 1 of sales) & $0.68^{*}$ \\
$\ln q_{i, t-2}$ & $($ lag 2 of sales) & $0.14^{*}$ \\
$\ln p_{i, t}$ & (price) & $-0.18^{* *}$ \\
$\ln m e s_{i, t} \times \ln p_{i, t}$ & (interaction) & $0.02 *$ \\
$\ln p c_{i, t}$ & (comp. price) & 0.10 \\
$\ln m e s_{i, t} \times \ln p c_{i, t}$ & (interaction) & $-0.01 * *$ \\
$\ln m e f_{i, t}$ & (flow) & $0.01 *$ \\
$\ln m e s_{i, t}$ & (stock) & $0.04^{*}$ \\
$\ln m e f c_{i, t}$ & (comp. flow) & $0.01 *$ \\
$\ln m e s c_{i, t}$ & (comp. stock) & $-0.03^{*}$ \\
\hline
\end{tabular}

$* p<0.05, * * p<0.10$ (two-tailed) 
b. on average, pharmaceutical marketing (flow and stock variables) increases demand;

c. on average, pharmaceutical marketing reduces price sensitivity of demand.

In their study, Windmeijer et al. (2005) assess the overall effect of an increase in own-brand and competitors' marketing expenditures by adding the corresponding flow and stock parameter estimates. They determine the long-term marketing elasticities as follows:

Long-term own-brand marketing elasticity $=\frac{\widehat{\alpha}_{5}+\widehat{\alpha}_{6}}{1-\widehat{\rho}_{1}-\widehat{\rho}_{2}}=0.3$.

Long-term cross-brand marketing elasticity $=\frac{\widehat{\alpha}_{7}+\widehat{\alpha}_{8}}{1-\widehat{\rho}_{1}-\widehat{\rho}_{2}}=-0.12$.

In addition, on the basis of the same outcomes (and the same data), De Laat et al. (2002) determine the market-making and market-stealing effects by considering both the effects of own marketing and competitors' marketing on sales. The net sales effect of a $1 \%$ increase of marketing expenditures by all players in a market is $(0.3-$ $0.12)=0.18 \%$. De Laat et al. (2002) further state that this is the market-making effect because market-stealing effects cancel out if all players increase their marketing expenditures equally. Then, the remaining $0.12 \%$ is the market-stealing effect. Thus, market making accounts for $60 \%$ of the total quantity effect and market stealing for $40 \%$.

The Rizzo model and its modifications are quite well accepted, and outcomes of empirical studies based on this model are generally interpreted as truths, as in Windmeijer et al. (2005). However, we have strong doubts about these outcomes because: ${ }^{1}$

1. the data are pooled across 140 brands and 11 markets;

2. marketing expenditures are aggregated;

3 . the inclusion of lagged endogenous variables present numerous (and welldocumented) empirical and conceptual problems; ${ }^{2}$

4. price fluctuations in The Netherlands (as in many other countries) are predominantly set by policy makers from government, industry, and insurance companies and are not directly set by pharmaceutical companies themselves.

In our empirical analysis, we will demonstrate that pooling over brands even within a submarket leads to biased parameter estimates. To this end, we use a subsample of the same dataset used by Windmeijer et al. (2005).

The meta-analysis by Kremer et al. (2008) demonstrates that the effect of different marketing efforts (journal advertising, detailing efforts, etc.) are substantially different from each other.

An important characteristic of this industry is the complex relationship between price charged by the manufacturers and quantity demanded by the patient due to the

\footnotetext{
${ }^{1}$ We thank one of the reviewers for the helpful comments in formulating our critisism

2 See, for example, Leeflang et al. (2000, pp. 85-98) and Van Heerde et al. (2000).
} 
existence of intermediate parties such as governments, health maintenance organizations, or private insurers (Manchanda et al. 2005, p. 301). In many European countries, intermediaries cover most of the cost of prescription drugs. This holds particularly for the time window which is considered in the calibrated models. Insured patients likely are not price sensitive and have little awareness of the retail price of their prescription. Physicians, working in the interest of patients, also do not have a financial stimulus to be price sensitive. Furthermore, they tend to be unaware of the retail price of specific drugs (Hurwitz and Caves 1988; Newhouse 1993). Gönül et al. (2001) find that considerations about drug efficacy and patients' conditions represent the primary drivers in the decision process, clearly overriding price concerns. Gonzalez et al. (2008) classify $83 \%$ of the physicians as being price insensitive. Hence, we have doubts about the inclusion of price and price interactions in pharmaceutical demand models which are calibrated using data from Western European countries.

In the next section, we specify alternative models that overcome these issues.

\section{Alternative specifications}

In the empirical part of this paper, we calibrate the model of Windmeijer et al. (2005) that we discussed in the previous section using a subset of the data of Windmeijer et al. We label this model as model 0 . We also estimate an unpooled, brand-specific version of model 0 and refer to this model as model 1:

$$
\begin{aligned}
\ln q_{i t}= & \gamma_{i}+\rho_{1 i} \ln q_{i, t-1}+\rho_{2 i} \ln q_{i, t-2}+\left(\alpha_{1 i}+\alpha_{2 i} \ln m e s_{i t}\right) \ln p_{i t} \\
& +\left(\alpha_{3 i}+\alpha_{4 i} \ln m e s_{i t}\right) \ln p c_{i t}+\alpha_{5 i} \ln m e f_{i t}+\alpha_{6 i} \ln m e s_{i t}+\alpha_{7 i} \ln m e f c_{i t} \\
& +\alpha_{8 i} \ln m e s c_{i t}+\beta_{i} X_{i t}+\varepsilon_{i t} .
\end{aligned}
$$

Model 1 overcomes the first issue that we raise in the previous section. In order to take the other issues into account, we specify alternative model structures to estimate the effects of marketing efforts on the demand for pharmaceutical products. In the next section, we discuss the outcomes of calibrating these models using monthly data from 49 brands of five product categories of the Dutch pharmaceutical market.

As a starting point, we specify model 2 , which is an alternative specification and based on Wittink (2002):

$$
\begin{aligned}
\ln q_{i t}= & \alpha_{0 i}+\alpha_{1} A g e_{i t}+\alpha_{2} A g e_{i t}^{2}+\alpha_{3} A g e_{i t}^{3}+\gamma_{1 k} \ln J A D_{i t}+\gamma_{2 k} \ln D E T_{i t} \\
& +\gamma_{3 k} \ln D M_{i t}+\gamma_{4 k}\left(\ln J A D_{i t} \times \ln D E T_{i t}\right)+\gamma_{5 k}\left(\ln J A D_{i t} \times \ln D M_{i t}\right) \\
& +\gamma_{6 k}\left(\ln D E T_{i t} \times \ln D M_{i t}\right)+\gamma_{7 k} \ln C J A D_{i t}+\gamma_{8 k} \ln C D E T_{i t}+\gamma_{9 k} \ln C D M_{i t} \\
& +\beta X_{i t}+u_{i t}
\end{aligned}
$$

where, for pharmaceutical product $i$ in month $t, A g e_{i t}$ is the age of the brand; $J A D_{i t}$ is the medical journal advertising expenditures; $D E T_{i t}$ is the detailing efforts; $D M_{i t}$ is the direct marketing efforts; $C J A D_{i t}$ is the competitive medical journal advertising 
expenditures; $C D E T_{i t}$ is the competitive detailing efforts; $C D M_{i t}$ is the competitive direct marketing efforts; $u_{i t}$ is the random disturbance term; and $q_{i t}$ and $X_{i t}$ as have been defined in Section 2. The index $k$ indicates the category to which brand $i$ belongs.

The intercept in model 2 is brand specific, but the parameters that represent marketing efforts effects are pooled across brands that belong to the same category $k$. In this respect, model 2 differs from model 1, which contains brand-specific parameters. This possibly alleviates our first issue. By including the third-order polynomial in Age we account for the diffusion pattern, thereby removing another source of differences between brands.

Model 2 also explicitly accommodates differences in effectiveness of the different marketing instruments (issue 2) and interactions between the marketing variables (Narayanan et al. 2004). Furthermore, this model also allows for differences in effectiveness of competitive instruments. Model 2 does not suffer from issues 3 and 5 as we did not include lagged sales and price as explanatory variables.

The second alternative specification is model 3 whose structure is similar to that of model 2. However, all parameters are now brand specific: the age parameters and the parameter vector $\beta$ receive an additional index $i$ and the index $k$ of the marketing efforts parameters is replaced by an index $i$. Hence, this model allows for a maximum level of heterogeneity.

In our final model, we simplify model 3 in the following ways: we lower the order of the polynomial in Age, we remove the interactions between the marketing mix instruments, and we aggregate the competitive marketing expenditures. This results in the following specification for model 4 :

$$
\begin{aligned}
\ln q_{i t}= & \alpha_{0 i}+\alpha_{1 i} A_{g e_{i t}}+\alpha_{2 i} A g e_{i t}^{2}+\gamma_{1 i} \ln J A D_{i t}+\gamma_{2 i} \ln D E T_{i t}+\gamma_{3 i} \ln D M_{i t} \\
& +\gamma_{4 i} \ln m e f c_{i t}+\beta_{i} X_{i t}+u_{i t} .
\end{aligned}
$$

Model 4 is a much more parsimonious model than model 3. Given that it is well known that there are synergies between various marketing instruments (Narayanan et al. 2004), we are aware that we may encounter problems in terms of model fit by omitting such interactions. More parsimonious models, however, will probably lead to better predictions (compare, e.g., Foekens et al. 1994). Another advantage of model 4 over model 3 is that it will not suffer from multicollinearity due to the inclusion of interactions.

\section{Empirical application}

We calibrate models 0-4 using monthly data covering the period 1994-1999 for 49 brands from five products categories of the Dutch prescription drug market. The dataset is an important subset of the dataset used by Windmeijer et al. (2005).

Model 0 is a basic model to many other models and has been used for public policy decision making. In Table 2, we present the outcomes of estimating model 0 using our data. Given that we have only a subset of the data of Windmeijer et al., the results are not identical to theirs (see Table 1). Specifically, we find a slightly stronger price coefficient, but an insignificant price--marketing interaction term. It is 
Table 2 Parameter estimates for the model of Windmeijer et al. (2005) using our data

\begin{tabular}{llr}
\hline Coefficient of & & Estimate \\
\hline $\ln q_{i, t-1}$ & (lag 1 of sales) & $0.13^{*}$ \\
$\ln q_{i, t-2}$ & $($ lag 2 of sales) & $0.12^{*}$ \\
$\ln p_{i, t}$ & (price) & $-0.45^{*}$ \\
$\ln m e s_{i, t} \times \ln p_{i, t}$ & (interaction) & 0.001 \\
$\ln p c_{i, t}$ & (comp. price) & $-0.19^{*}$ \\
$\ln m e s_{i, t} \times \ln p c_{i, t}$ & (interaction) & $0.02^{*}$ \\
$\ln m e f_{i, t}$ & (flow) & $0.02^{*}$ \\
$\ln m e s_{i, t}$ & (stock) & $0.05^{*}$ \\
$\ln m e c_{i, t}$ & (comp. flow) & $-0.03^{*}$ \\
$\ln m e s c_{i, t}$ & (comp. stock) & $-0.01^{*}$ \\
\hline
\end{tabular}

${ }^{*} p<0.05$ (two-tailed)

also noteworthy that the competitive price coefficient is negative and significant, which is unexpected.

Table 3 summarizes for each of the parameters of model 1 the variation in the brand-specific estimation results. The column labeled "mean" indicates the mean value of the 49 parameter estimates; the columns labeled $p_{0.05}$ and $p_{0.95}$ show the fifth and 95th percentiles of the set of parameter estimates, respectively; and the column labeled "fraction significant and correct sign" indicates the fraction of parameters statistically different from zero with the right sign. Only five of the 49 own-price and cross-price elasticities are significant and have the appropriate sign. We do not observe interaction effects of own-price and marketing expenditures that are significant and have a positive sign.

To determine whether pooling of individual brand-level outcomes is allowed, we conduct a Roy-Zellner pooling test separately for each of the five markets. ${ }^{3}$ We provide the $F$ values and corresponding critical values in Table 4 . We conclude that, for each of the five submarkets, the null hypothesis of poolability is rejected. Using the same test, we find that pooling is not appropriate for the full set of data either. Therefore, the estimates of pooled relations cannot be used to characterize brand behavior.

We present brand-level estimation results for each of the five markets in Table 5. To conserve space, we only show the average coefficients for each market rather than the percentiles and fractions of correctly signed and significant coefficients. However, only three out of 50 percentile intervals corresponding to each of the 50 averages in Table 5 exclude zero. The variation in the coefficients in each row of Table 5 provide a further illustration that pooling is not appropriate, not within submarkets (Table 4), let alone across markets (Table 5).

In Table 6, we summarize the Akaike information criterion (AIC) and the Bayesian information criterion (BIC) values of models 1, 3, and 4. AIC and BIC values of model 0 and 2 are not presented due to the pooled nature of these models.

\footnotetext{
3 This test can be considered as a generalization of the Chow (1960) test and is recommended in cases in which there is possible heteroskedasticity (Baltagi 2005).
} 
Table 3 Brand-level results of the model of Windmeijer et al. (2005) (49 brands)

\begin{tabular}{llrrrc}
\hline Coefficient of (expected sign) & & Mean & $p_{0.05}$ & $p_{0.95}$ & $\begin{array}{c}\text { Fraction significant } \\
\text { and correct sign }\end{array}$ \\
\hline $\ln q_{i, t-1}$ & & & & & 0.16 \\
$\ln q_{i, t-2}$ & lag 1 of sales (+) & 0.02 & -0.05 & 0.17 & 0.24 \\
$\ln p_{i, t}$ & lag 2 of sales (+) & 0.05 & -0.01 & 0.38 & 0.10 \\
$\ln m e s_{i, t} \times \ln p_{i, t}$ & price (-) & -0.10 & -1.09 & 0.94 & 0 \\
$\ln p c_{i, t}$ & interaction (+) & -0.05 & -1.12 & 0.39 & 0.10 \\
$\ln m e s_{i, t} \times \ln p c_{i, t}$ & comp. price (+) & 0.50 & -1.57 & 5.08 & 0.08 \\
$\ln m e f_{i, t}$ & interaction (-) & -0.05 & -0.42 & 0.13 & 0.10 \\
$\ln m e s_{i, t}$ & flow (+) & 0.01 & -0.02 & 0.05 & 0.02 \\
$\ln m e c_{i, t}$ & stock (+) & -0.07 & -1.47 & 0.21 & 0 \\
$\ln m e s c_{i, t}$ & comp. flow (-) & 0.07 & -0.03 & 0.30 & 0.06 \\
\hline
\end{tabular}

We conclude that the in-sample fit of model 1 is best, followed by models 3 and 4 . The comparison between models 3 and 4 indicates that the inclusion of interaction terms leads to a better (in-sample) fit when we look at AIC values. However, if we consider BIC values (which penalize the number of variables more heavily), model 4 is preferred.

In Table 7, we present a comparison of the predictive validity of the competing models. We estimated models $0-4$ again, now excluding the last five observations of each brand. Subsequently, the last five observations were predicted using the calibrated models. We use the mean absolute percentage error (MAPE) as our measure of predictive validity.

Table 7 shows that the brand-specific models outperform the pooled models in terms of predictive validity, supporting the conclusion that pooling is not appropriate. Model 4, the simplest model, has the best predictive validity. Models 2 and 3 suffer from multicollinearity due to the inclusion of many interactions. The simpler model 4 is much less subject to this problem. This may explain why the predictive validity of this model is best.

In Table 8, we summarize the findings of model 4 . For each of the variables, we report the mean, the fifth and the 95th percentiles, and the fraction of brands for which the estimated parameters have the expected sign and are significant.

Table 4 Roy-Zellner pooling test per submarket

\begin{tabular}{lcc}
\hline Submarket & $F$ value & Critical value \\
\hline Ulcers & 28.1 & 1.24 \\
Hypertension & 60.2 & 1.11 \\
Cholesterol & 40.6 & 1.23 \\
Depression & 59.9 & 1.25 \\
Asthma & 61.6 & 1.31 \\
\hline
\end{tabular}


Table 5 Brand-level results of the model of Windmeijer et al. (2005), averaged per submarket

\begin{tabular}{|c|c|c|c|c|c|c|}
\hline Coefficient of & & Ulcers & Hypertension & Cholesterol & Depression & Asthma \\
\hline $\ln q_{i, t-1}$ & (lag 1 of sales) & -0.0002 & -0.0003 & 0.02 & 0.09 & 0.001 \\
\hline $\ln q_{i, t-2}$ & (lag 2 of sales) & -0.001 & 0.03 & 0.05 & 0.10 & -0.005 \\
\hline $\ln p_{i, t}$ & (price) & 0.15 & -0.15 & -0.54 & -0.32 & -0.13 \\
\hline $\ln m e s_{i, t} \times \ln p_{i, t}$ & (interaction) & 0.05 & -0.08 & -0.27 & -0.26 & -0.01 \\
\hline $\ln p c_{i, t}$ & (comp. price) & 1.17 & -1.05 & 1.11 & 6.60 & 0.10 \\
\hline $\ln m e s_{i, t} \times \ln p c_{i, t}$ & (interaction) & -0.07 & 0.09 & -0.13 & -0.56 & -0.01 \\
\hline $\ln m e f_{i, t}$ & (flow) & 0.01 & 0.01 & 0.002 & -0.02 & 0.01 \\
\hline $\ln m_{e s} s_{i, t}$ & (stock) & -0.15 & 0.10 & -0.08 & -0.51 & -0.03 \\
\hline $\ln m e f c_{i, t}$ & (comp. flow) & 0.21 & 0.06 & 0.08 & 0.05 & 0.001 \\
\hline $\ln \operatorname{mesc}_{i, t}$ & (comp. stock) & -0.10 & -0.03 & -0.18 & -0.02 & 0.03 \\
\hline
\end{tabular}

We conclude that the age variables describing the product life cycle patterns in the sales data are significant for most of the brands. Own-marketing effects are much less often right-signed and significant, and significant competitive effects with the right sign are not present at all. It appears that detailing is effective for more brands than the other instruments. However, the effects sizes are modest and occur infrequently. This corresponds with the meta-analytic findings of Kremer et al. (2008).

Comparing Table 8 to the pooled outcomes of model 0 in Table 2, we conclude that the brand-level analysis is not in agreement with the much stronger results that the pooled analysis appears to indicate. Specifically, the pooled outcomes indicate significant effects of marketing expenditures, whereas the brand-level results show that these are absent for the majority of the brands. We conclude that the pooled outcomes do not provide adequate descriptions of reality and should not be used for decision making and certainly not for policy making.

\section{Discussion and conclusions}

The past decade has seen increased activity dedicated to modeling the effects of marketing expenditures on sales in the pharmaceutical industry. Because the outcomes of these studies can have important consequences for decision making by pharmaceutical companies and governments, we critically evaluate the structure

Table 6 Summary of AIC and BIC values for models 1, 3, and 4

\begin{tabular}{lcc}
\hline Model & Mean (SD) of AICs & Mean (SD) of BICs \\
\hline Model 1 & $-172.3(93.6)$ & $-93.1(90.2)$ \\
Model 3 & $-144.3(114.0)$ & $-62.9(111.7)$ \\
Model 4 & $-130.7(129.7)$ & $-64.1(127.9)$ \\
\hline
\end{tabular}


Table 7 Summary of the predictive validity of models $0-4$

Model

Model 0

Model 1

Model 2

Model 3

Model 4
Mean (SD) of MAPEs

$94.0(203.3)$

22.4(28.6)

$36.2(32.4)$

$18.4(18.4)$

$14.9(13.4)$

and outcomes of an important and widely accepted model. Specifically, we consider a recent study by Windmeijer et al. (2005), which attempts to determine the effects of pharmaceutical promotions on GP prescribing behavior.

We replicate the study using a substantial set of the data used by Windmeijer et al. However, in contrast to Windmeijer et al., we also determine the effects of promotions at the individual brand level. Our empirical outcomes do not confirm their findings. Rather, the parameter estimates of the individual brand-level models are so different that pooling across brands, even within the same category, is inappropriate, which further implies that we cannot confirm the conclusions of Windmeijer et al. Specifically, we cannot confirm that:

a. premarketing own-brand price elasticities are negative;

b. pharmaceutical marketing reduces the price elasticity of demand; or

c. pharmaceutical marketing increases demand.

The conclusion that price does not affect demand for the large majority of the brands in our study is in line with earlier findings that physicians' decisions are driven by medical concerns and not by price (see, e.g., Gönül et al. 2001). This is a consequence of the almost-perfect insurance coverage in The Netherlands: neither for patients nor for physicians, there is a financial stimulus to be price sensitive. Furthermore, pharmaceutical prices are strongly regulated so that price fluctuations are scarce and small.

We also do not find evidence that marketing expenditures reduce price sensitivity. This effect of marketing is known as the persuasive function of marketing (Leffler 1981; Hurwitz and Caves 1988) and is unwanted because, ceteris paribus, doctors

Table 8 Summary of results of model 4 (49 brands)

\begin{tabular}{llcccc}
\hline Coefficient of (expected sign) & & Mean & $p_{0.05}$ & $p_{0.95}$ & $\begin{array}{c}\text { Fraction significant } \\
\text { and correct sign }\end{array}$ \\
\hline Age $_{i t}$ & age (+) & 0.17 & 0.09 & 0.30 & 1 \\
Age $_{i t}^{2}$ & age squared (-) & -0.0006 & -0.0019 & -0.00001 & 0.65 \\
$\ln J A D_{i t}$ & journal adv. (+) & 0.027 & -0.007 & 0.051 & 0.06 \\
$\ln D E T_{i t}$ & detailing (+) & 0.014 & -0.047 & 0.050 & 0.10 \\
$\ln D M_{i t}$ & direct mail (+) & 0.007 & -0.070 & 0.027 & 0.04 \\
$\ln m e c_{i t}$ & comp. flow (-) & 0.053 & -0.067 & 0.257 & 0 \\
\hline
\end{tabular}


should choose the cheapest alternative (De Laat et al. 2002, p. 60). If marketing expenditures would make physicians less price sensitive this could be interpreted as increasing "brand loyalty not supported by product characteristics" (De Laat et al. 2002, p. 80). In turn, this may lead to higher prices, thereby harming social welfare (Windmeijer et al. 2005). Consequently, the welfare implications of our findings are fundamentally different from those of Windmeijer et al. (2005). We cannot confirm that marketing has negative welfare effects due to reducing the price elasticity of demand. Instead, we find that, on average, the marketing-price interaction is negative, which is an indication of the informative function of marketing (Leffler 1981). This has interesting policy implications. There is no need for policy options aiming at increasing price sensitivity (see, e.g., de Laat et al. 2002) to fight the proclaimed persuasive effects of marketing. Instead, the informative function of marketing can be stimulated.

Our findings that result from estimating better alternative models show that marketing effects are insignificant for the majority of the brands in our sample and that their sizes are modest. Our findings further suggest that it is useful for pharmaceutical researchers and practitioners to accommodate differences in promotional instruments (cf., Kremer et al. 2008). This may have important managerial implications, as it may help marketing managers to improve the allocation of their marketing budgets over the different instruments, thereby reducing the waste in marketing investments. Furthermore, we find that the stage of the product life cycle should be taken into account. In the models that are discussed in this paper, product life cycle patterns are represented by some variables in $X_{i t}$ or by explicitly taking age variables into account. We also find that, for the set of brands that we consider, pooled models are neither suited for descriptive purposes nor for predictive purposes. Instead, simpler, brand-level models have better predictive validity.

The parameters in models $0-4$ are assumed to be constant over time. Extant empirical research in which the authors of this paper participate (Osinga et al. 2009; Ruiz Conde et al. 2009) shows that parameters are not constant over the product life cycle. This implies that varying parameter models offer opportunities to obtain better descriptions and predictions than the models which are discussed in this paper to model the effects of pharmaceutical marketing expenditures on sales.

Acknowledgements The authors thank Nefarma, the Dutch Association of the Innovative Pharmaceutical Industry, for providing funding to acquire the data for the replication study.

Open Access This article is distributed under the terms of the Creative Commons Attribution Noncommercial License which permits any noncommercial use, distribution, and reproduction in any medium, provided the original author(s) and source are credited.

\section{References}

Baltagi, B. H. (2005). Econometric analysis of panel data (3rd ed.). Chichester: Wiley.

Catlin, A., Cowan, C., Heffler, S., Washington, B., \& The National Health Expenditure Accounts Team. (2007). National health spending in 2005: The slowdown continues. Health Affairs, 26(1), 142-153.

Chow, G. C. (1960). Tests of equality between sets of coefficients in two linear regressions. Econometrica, 28(3), 591-605. 
CMS. (2009). National health expenditures aggregate amounts and average annual percent change, by type of expenditure: Selected calendar years 1960-2007. Retrieved June 24, 2009 from http://www.cms. hhs.gov/NationalHealthExpendData/downloads/tables.pdf.

De Laat, E., Windmeijer, F., \& Douven, R. (2002). How does pharmaceutical marketing influence doctors' prescription behaviour? The Hague: CPB Netherlands' Bureau for Economic Policy Analysis.

Foekens, E. W., Leeflang, P. S. H., \& Wittink, D. R. (1994). A comparison and an exploration of the forecasting accuracy of a loglinear model at different levels of aggregation. International Journal of Forecasting, 10, 245-261.

Gönül, F. F., Carter, F., Petrova, E., \& Srinivasan, K. (2001). Promotion of prescription drugs and its impact on physicians' choice behavior. Journal of Marketing, 65, 79-90.

Gonzalez, J., Seismero, C., Dutta, S., \& Stern, P. (2008). Can branded drugs benefit from generic entry? The role of detailing and price in switching to non-bioequivalent molecules. International Journal of Research in Marketing, 25, 247-260.

Hurwitz, M. A., \& Caves, R. E. (1988). Persuasion or information? Marketing and the shares of brand name and generic pharmaceuticals. Journal of Law and Economics, 31, 299-320.

Kremer, S. T. M., Bijmolt, T. H. A., Leeflang, P. S. H., \& Wieringa, J. E. (2008). Generalizations on the effectiveness of pharmaceutical promotional expenditures. International Journal of Research in Marketing, 25, 234-246.

Leeflang, P. S. H., Wittink, D. R., Wedel, M., \& Naert, P. A. (2000). Building models for marketing decisions. Boston: Kluwer Academic.

Leffler, K. (1981). Persuasion or information? The economics of prescription drug advertising. Journal of Law and Economics, 24(1), 45-74.

Ling, D. C., Berndt, E. R., \& Kyle, M. K. (2002). Deregulating direct-to-consumer marketing of prescription drugs: Effects on prescription and over-the-counter product sales. Journal of Law and Economics, 45(2), 691-723.

Manchanda, P., Wittink, D. R., Ching, A., Cleanthous, P., Ding, M., Dong, X., et al. (2005). Understanding firm, physician and consumer choice behavior in the pharmaceutical industry. Marketing Letters, 16(3/4), 293-308.

Narayanan, S., Desiraju, R., \& Chintagunta, P. K. (2004). ROI implications for pharmaceutical promotional expenditures: The role of marketing mix interactions. Journal of Marketing, 68(4), 90105 .

Narayanan, S., Manchanda, P., \& Chintagunta, P. K. (2005). Temporal differences in the role of marketing communication in new product categories. Journal of Marketing Research, 42(3), 278-290.

Newhouse, J. P. (1993). Free for all? Lessons from the RAND Health Insurance Experiment. Cambridge: Harvard University Press.

Osinga, E. C., Leeflang, P. S. H., \& Wieringa, J. E. (2009). The persistency of marketing effects over the brand's life cycle. Journal of Marketing Research, forthcoming.

Peters, C. P. (2004). Fundamentals of the prescription drug market. NHPF Background Paper 2004. Retrieved October 25, 2007 from http://www.nhpf.org/pdfs_bp/BP_RxIndustry_08-24-04.pdf.

Rizzo, J. A. (1999). Advertising and competition in the ethical pharmaceutical industry: The case of antihypertensive drugs. Journal of Law and Economics, 42, 89-116.

Rosenthal, M. B., Berndt, E. R., Donohue, J. M., Epstein, A. M., \& Frank, R. G. (2003). Demand effects of recent changes in prescription drug promotion. In D. M. Cutler \& A. M. Garber (Eds.), Frontiers in health policy research (Vol. 6, pp. 1-26). Cambridge: MIT.

Ruiz Conde, E., Wieringa, J. E., \& Leeflang, P. S. H. (2009). Longitudinal and cross-sectional effects of marketing instruments on diffusion of pharmaceuticals. Working paper, University of Groningen.

Stremersch, S. (2008). Health and marketing: The emergence of a new field of research. International Journal of Research in Marketing, 24, 229-233.

Van Heerde, H. J., Leeflang, P. S. H., \& Wittink, D. R. (2000). The estimation of pre- and postpromotion dips with store-level scanner data. Journal of Marketing Research, 37(3), 383-395.

Venkataraman, S., \& Stremersch, S. (2007). The debate on influencing doctors' decisions: are drug characteristics the missing link? Management Science, 53(11), 1688-1701.

Windmeijer, F., De Laat, E., Douven, R., \& Mot, E. (2005). Pharmaceutical promotion and GP prescription behaviour. Health Economics, 15(1), 5-18.

Wittink, D. R. (2002). Analysis of ROI for pharmaceutical promotion (ARPP). Retrieved October 25, 2007 from http://www.rxpromoroi.org/arpp/index.html. 